\title{
LA AUTOBIOGRAFÍA: MODELO NARRATIVO DE LA NOVELA PICARESCA EN LA COLINA DEL BUEY (1972), DE JOSÉ LEÓN SÁNCHEZ
}

\author{
The Autobiography: Narrative Model of Picaresque Novel in La colina del \\ buey (1972), by José León Sánchez
}

Baruc Chavarría Castro*

A la memoria de J. J. Marín Hernández

\begin{abstract}
RESUMEN
La novela Picahueso (1971), la segunda escrita por José León Sánchez, después titulada La colina del buey (1972), ha sido asociada al modelo narrativo de la picaresca española, pero no se había estudiado en detalle. Las características estructurales determinadas por la teoría acerca del género picaresco son reconocibles en la narración de J. L. Sánchez, entre ellas la más importante: la autobiografía. A partir de esta característica fundamental, se plantea estudiar de qué manera es escrito el material vital del protagonista, Manuel Miranda Miranda, alias Picahueso. Aunque se reconoce la utilidad de conceptos estructurales presentes en el relato, el acercamiento a la novela es metodológicamente comparativo. Se considera que lo autobiográfico es manejado de modo distinto, convirtiendo la escritura del yo, en una escritura del otro, en una otobiografía.
\end{abstract}

Palabras clave: Literatura costarricense, literatura comparada, deconstrucción, otobiografía.

ABSTRACT

The novel Picahueso (1971), the second one written by José León Sánchez and later titled La colina del buey (1972), has been associated with the narrative model of Spanish picaresque. This aspect, however, has not been studied in detail. The structural characteristics determined by the theory about the picaresque genre are recognizable in J. L. Sánchez's narrative, among them the most important one: autobiography. Based on this fundamental characteristic, it is proposed to study how the vital material of the protagonist, Manuel Miranda Miranda, aka Picahueso, is written. Although the usefulness of structural concepts present in the story is recognized, the approach to the novel is methodologically comparative. It is considered that the autobiographical is handled in a different way, turning the writing of the self into the writing of the other; into an otobiography.

Key Words: Costa Rican literature, comparative literature, deconstruction, otobiography.

\footnotetext{
* Universidad de Costa Rica. Máster en Literatura Latinoamericana, docente de la Sede del Pacífico e investigador del Centro de Investigaciones Históricas de América Central (Cihac, UCR), Costa Rica.

Correo electrónico: Baruc.chavarria@ hotmail.com
}

Recepción: 27/02/2018. Aprobación: 26/04/2018. 


\section{Introducción}

Entre los textos de José León Sánchez, la novela La colina del buey es la más sui géneris. Su singularidad se marca, por ejemplo, desde su primera publicación con el título Picahueso, del año 1971, luego de conseguir el premio Juegos Florales Centroamericanos 1968.1 Es en su siguiente edición del año 1972 que se edita con el título actual. Respecto de los temas que este autor ha desarrollado en su escritura, esta novela no presenta mayor divergencia, pues la marginalidad, el valor documental, histórico y testimonial están contenidos en la historia de Picahueso y son reconocidos por la crítica que ha leído este texto de J. L. Sánchez (Cañas-Escalante, 1971; Láscaris-Comneno, 1971; García-Murillo, 1974; Chase-Brenes, 1975; Sandoval-de Fonseca, 1978). En un trabajo más reciente, Álvaro Quesada Soto (2008) sintetiza de la siguiente manera los motivos predominantes en la narrativa de J. L. Sánchez:

Las novelas de J. L. Sánchez retoman de la novela del 40 la preocupación por testimoniar —desde el punto de vista de los personajes marginados-ámbitos periféricos de la historia o la vida social: el presidio de San Lucas en La isla de los hombres solos (1963), los enclaves mineros de Abangares en La colina del buey (1972), o la conquista de México desde el punto de vista de los aztecas en Tenochtitlan (1986) (Quesada Soto, 2008, p. 105).

Precisamente, el tema del enclave minero en Abangares es lo primero que llama la atención en $L a$ colina del buey. Con su segunda novela, J. L. Sánchez se coloca en una tradición de literatura minera cuya sistematización sigue pendiente.2 En esa línea no revisada de la historiografía costarricense, inaugurada por las novelas Tierras de sol (1935), de Rubén Yglesias Hogan, y Alma llanera (1946), de Edelmira González, la experiencia de Manuel Miranda Miranda, conocido como Picahueso, toma también su sitio en las minas de Abangares. Y no es un detalle menor apuntar la falta de un trabajo

1 El jurado estuvo compuesto por Carlos Luis Sáenz, León Pacheco, Guido Fernández y Jézer González; también hubo una representación de la Editorial Costa Rica con Rosa María v. de Bonilla Baldares, Samuel Rovinski y Jézer González; por último, el texto original fue revisado por los asesores en historia, Emma Gamboa, Carlos Meléndez Chaverri y Mario González Feo.

2 Actualmente, se edita un trabajo de recopilación y descripción de este corpus de literatura minera costarricense, el cual abarca poco más de un siglo y se compone de 22 obras, entre narrativa, crónica, drama y lírica. 
descriptivo de este corpus de literatura sobre minas, cuyo inicio como temática se remonta al año 1910 con el cuento "El minero", de Juan Garita, y su alcance llega hasta la publicación de Avancari (2012), del escritor Santiago Porras.

\section{Acercamiento a la estructura del relato}

Dejando a un lado el contenido para desarrollar la atención sobre la forma de la novela, la construcción literaria de Picahueso, narrador y protagonista, ha sido relacionada positiva o negativamente con la estructura de la picaresca clásica española. A poco tiempo de la primera edición, Alberto Cañas Escalante (1971) dedica en su columna semanal del periódico La República un comentario acerca de la novela y opina de Picahueso que era: "un personaje de episodios picarescos que no es un pícaro, sino, simplemente, un errante” (p. 8). Mientras que Constantino Láscaris Comneno (1971), en el prólogo a esa primera edición, señala que J. L. Sánchez “aprovecha los distintos trabajos de este honrado y laborioso pícaro para ir describiendo el país” (p. xiii).

En efecto, la relación de la estructura del texto con el modelo quinientista es rastreable y hasta puede llevar a confusión el mote del protagonista, Picahueso, con el término pícaro, pero este no es el caso. Tampoco es una ocurrencia señalar tal comunicación entre la narrativa contemporánea y el Lazarillo de Tormes (1554); por el contrario, el género picaresco es de los pocos fenómenos literarios que en la tradición crítica hispana ha despertado la atención de diferentes corrientes. Por ejemplo, Luis Villamía (2011), quien realiza una de las revisiones más recientes sobre teoría del género picaresco, señala tres líneas teóricas muy definidas: la referencialista (centrada en los contenidos), la estructuralista (centrada en la forma) y la perspectiva comparatista (síntesis de contenido y forma).

Desde la perspectiva comparada, con autores como Claudio Guillén (1989) y Antonio Rey Hazas (1990) se admite una lectura de textos contemporáneos cercanos a la tradición picaresca. Por ejemplo, Guillén propone el concepto de interhistoricidad para interpretar textos escritos en distintos momentos históricos, pero que ofrecen marcas de intermitencia, ruptura, recuperación, interrupción 
y reescritura (p. 289), tomando como paradigma de su tesis precisamente la novela picaresca. Por su parte, Rey Hazas, a partir de los aportes de Parker, Maravall, Rico, Carreter y Guillén, entre otros autores, sintetiza en su propuesta aspectos formales y de contenido que posibilitan comprender una continuidad de la picaresca en producciones literarias contemporáneas. En otras palabras, ambos autores defienden una tradición originada en el siglo XVI que continúa viva gracias a reelaboraciones propias de la práctica literaria.

De manera que es el enfoque comparativo, con sus ventajas y limitaciones, el que interesa para abordar La colina del buey, pues es el único que plantea una apertura del canon y permite la lectura de la autobiografía a la luz del esquema narrativo de la picaresca. A partir de las consideraciones teóricas de Rey Hazas (1990) acerca de la picaresca, en Manuel Miranda Miranda, alias Picahueso, son identificables los rasgos más importantes que admitirían una lectura de este personaje minero cercana a la del pícaro literario. Características como la actitud antiheroica, la encarnación del deshonor, la libertad, la genealogía vil, el hambre, la miseria y la delincuencia, la representación de un mundo adverso y la soledad radical, constituyen literariamente a Picahueso tanto como al Lazarillo.

Para ilustrar una de las condiciones señaladas, el siguiente fragmento relacionado con la actitud del antihéroe es importante. Recién llegado a la zona minera, con 14 años y junto a un amigo cuatro años mayor, Manuelillo — como primero se le conoce a Manuel Miranda Miranda, antes de ser Picahueso- presencia un asesinato a cuchilladas, luego de una pelea entre dos pretendientes de una mujer. Cuando la policía llega detiene a todos; el primer interrogado es su amigo Juan, quien niega haber visto algo o a alguien; así, cuando le llega su turno, y a pesar de saberse mintiendo, Manuelillo imita a su amigo por considerarlo más experimentado. De vuelta en sus asuntos y después de ser liberados, Juan le explica:

-Pues que te sirva de lección: allá en San José hay tribunales, justicia y muchas cosas más. Aquí todo cambia y hay cosas que no las cura, ni el Cura. Por lo tanto, lo que has hecho hoy, 
debes de hacerlo siempre: no ver nada, no escuchar, no hablar. Y ya has de ver lo mucho que el consejo ha de servirte (Sánchez, 1971, p. 62).

Como menciona Francisco Rico (1989) en su estudio sobre la picaresca española, la actitud del antihéroe se caracteriza por "callar y quedarse al margen cuando conviene, la del silencio en provecho propio" (p. 35). En el fragmento citado, además de mostrarse la actitud antiheroica como rasgo del personaje protagonista en La colina del buey, el consejo de Juan a Manuelillo recuerda la anécdota del Lazarillo con el ciego, su primer maestro, a la salida de Salamanca. Cuando se disponen a abandonar la ciudad, el ciego invita al niño a acercar su oído a la figura de piedra que está sobre el puente, con el engaño de que se escucha un gran ruido dentro:

Yo simplemente llegué, creyendo ser así. Y como sintió que tenía la cabeza par de la piedra, afirmó recio la mano y diome una gran calabazada en el diablo del toro, que más de tres días me duró el dolor de la cornada, y díjome:

-Necio, aprende, que el mozo del ciego un punto ha de saber más que el diablo (Anónimo, 1957, p. 39).

De manera que no solo la actitud antiheroica resulta primordial en la constitución de ambos personajes, Manuelillo y el Lazarillo, sino que los dos deben aprender el modo de sobrevivir en un entorno adverso y, sin embargo, para el cual están predestinados debido a dos condiciones también compartidas: su orfandad y genealogía vil, pues sus padres son condenados por hurto y mueren en el destierro (Anónimo, 1957, p. 35; Sánchez, 1971, p. 4). Es a muy temprana edad que deben valerse por su cuenta y, como sabiamente aconsejan Juan y el ciego, les toca ver por su propio provecho mediante la astucia.

\section{El manejo del esquema autobiográfico en la novela}

Así como ocurre con la construcción del personaje literario, en esta novela de J. L. Sánchez hay muchos puntos de coincidencia con la tradición picaresca española en el plano estructural; no obstante, el problema de esta ponencia está acotado al de la autobiografía, que como elemento formal ha preocupado tanto a la línea teórica estructuralista como a la comparatista. Enfocando la estructura 
de la novela, La colina del buey se plantea como autobiografía desde la primera línea: "Yo he sido borracho, jugador, enamorado y peleador", afirma quien de inmediato se identifica: “Tengo 72 años y se me ha conocido por Manuel Miranda Miranda, alias Picahueso” (Sánchez, 1971, p. 1). Antes de continuar, valga mencionar dos detalles: por un lado, el uso del alias en la manera de presentarse del personaje, lo cual lo ubica en el ámbito marginal y casi en el mundo del crimen; por otro lado, este inicio también recuerda el del modelo quinientista: "Pues sepa vuestra merced, ante todas cosas, que a mí llaman Lázaro de Tormes, hijo de Tomé González y de Antona Pérez, naturales de Tejares, aldea de Salamanca" (Anónimo, 1957, p. 35).

De vuelta al "Yo he sido" con que Manuel Miranda Miranda, alias Picahueso, comienza la relación de su vida, el pretérito perfecto compuesto define un rasgo del pasado que continúa hasta un presente determinado por el tiempo desde el cual se narra. En esa dimensión de la estructura del relato, quedan en firme dos de las condiciones delineadas por Francisco Rico (1989) respecto de la estructura cerrada de la novela picaresca: autobiografía y punto vista. De acuerdo con Rico (1989, p. 24), el elemento central que daría sentido y cohesionaría la narración como unidad cerrada sería el caso, el cual exigiría tanto el esquema de la autobiografía como la coherencia del punto de vista. En resumen, el caso es el pretexto, lo que hace al yo escribir la historia de su vida.

En La colina del buey, la autobiografía se afianza en el punto de vista de Manuel Miranda Miranda. Uno de los efectos más remarcables de esa cohesión entre autobiografía y punto de vista en la novela de J. L. Sánchez es el uso de un deíctico modal que se repite a lo largo del texto, cuya insistencia puede parecer más bien incoherente o revelar un vacío de información, pero que más adelante opera en el sentido contrario. Una definición de diccionario para comprender los deícticos es que son elementos lingüísticos o léxicos que sirven para señalar y referirse a lo presente (Lewandowski, 1982). Por ejemplo, Manuelillo menciona: "Me asustaba mucho viendo a doña Pánfila con esos aspavientos, pero Rafaelillo que era así de grande y mayor que yo, comentaba que no le hiciera caso pues ella afirmaba eso por ser una vieja" (Sánchez, 1971, p. 8; la cursiva es agregada). 
El recurso del deíctico modal "asî” en el fragmento citado carece de una referencia suficiente en el texto para que la idea esté completa, como sucede en el siguiente fragmento: "La mujer salió de repente y tomándome de las manos me llevó hasta detrás de un cerco, en donde tocándome así y así y diciendo palabras bonitas, terminó por levantarse las enaguas” (Sánchez, 1971, pp. 9-10; la cursiva es agregada). A partir de este otro ejemplo, surge la pregunta: ¿si se trata de una escritura del yo, esto es, de una autobiografía, por qué la deixis no es textual sino ostensiva, o sea, que su significado depende de un gesto o de información extratextual?

Conforme se avanza, la gestualidad adquiere un peso cada vez más relevante en la narración: “Algo que me abría los ojos así de grandes, era la hora del recreo" (Sánchez, 1971, p. 23; la cursiva es agregada). El uso del deíctico modal en la novela descubre unas manos que no escriben, sino que apoyan gestualmente la narración y, por lo tanto, el esquema de la autobiografía como escritura del yo se desestabiliza en el mismo texto. El tema autobiográfico se complejiza cuando a mitad de su relato el narrador confiesa que sabe leer muy poco (Sánchez, 1971, p. 82) y posteriormente repite que no sabe escribir. De manera que la cuestión inmediata que se agrega a la pregunta anterior es: ¿si no es él de su puño y letra, entonces quién escribe la autobiografía de Manuel Miranda Miranda? Cerca del final, un solo fragmento revela tanto el caso o pretexto de la narración de Picahueso, como el artificio que llena de sentido el recurso de la deixis ostensiva a lo largo del relato:

Pica, siempre has sido buen conversador. Te voy a traer unos cuadernos para que con la ayuda de algún compañero, escribas tus «memorias». Fue él quien me trajo estos cinco cuadernos, en donde he ido contando esta historia.

Tengo ya mucho tiempo de estarla contando. Me la empezó a escribir Celestino Porras, hasta que murió. Luego ha tenido como diez escribientes y por eso es que hay mucha clase de letras. Aquí voy contando mi vida y Monge cree que lo hago bien (Sánchez, 1971, p. 201).

Por una parte, el fragmento permite identificar que el pretexto de la narración, el caso como concepto estructural, es la petición de Monge, un antiguo amigo de Manuel Miranda Miranda, para que escriba sus memorias. Por otra parte, se aclara el proceso de escritura, pues Picahueso no escribe, sino que dicta sus memorias a otros escribientes, enfermos tuberculosos del hospital donde pasa sus últimos 
días. El punto de vista se afirma en la presencia de Manuel Miranda Miranda frente a sus escribientes, con lo cual el uso de la deixis ostensiva adquiere sentido si se entiende la narración autobiográfica como un dictado enriquecido por la gestualidad de un buen conversador, como Picahueso es reconocido por su amigo. De modo que la autobiografía como escritura del yo termina por dar paso a una escritura del otro, en este caso los varios escribientes que reciben el dictado del narrador protagonista.

\section{Consideración parcial}

Este artículo se desprende de un proyecto de tesis más amplio que primero plantea una lectura comparativa de La colina del buey desde la teoría de la picaresca, para luego deconstruir esa misma propuesta de lectura (Chavarría Castro, 2018). Se parte de que los conceptos del enfoque comparativo sobre la picaresca para analizar las producciones literarias recientes siguen siendo deudores de las tesis estructuralistas acerca del género, y de que el mismo género picaresco es una invención que debe deconstruirse. En este caso, se anticipa una de las discusiones que aborda el problema de la autobiografía como elemento central en la definición del género y la teoría sobre la picaresca.

Para Jacques Derrida hay una imposibilidad en toda autobiografía, porque esta supone la existencia de un yo, mientras que ese yo no sería más que un efecto del lenguaje en la consciencia y, por lo tanto, podría identificarse y predicarse solo dentro de los límites de la metafísica. A partir de su lectura del Ecce Homo de Nietzsche, Derrida (1985) desplaza el prefijo autos de la autobiografía por el oto, que es la oreja y, en este caso, la oreja del otro que, por ejemplo, escucha el dictado de Manuel Miranda Miranda. En ese gesto de incluir la noción del otro mediante su oreja en el proceso de la escritura del yo, simultáneamente se coloca el tema de la firma y la muerte, porque ya no será Manuel Miranda Miranda quien firme la narración de su vida, sino uno entre tantos escribientes, un otro que escucha, escribe sus memorias y lo ve morir: 
The ear of the other says me to me and constitutes the autos of my autobiography. When, much later, the other will have perceived with a keen-enough ear what I will have addressed or destined to him or her, then my signature will have taken place (Derrida, 1985, p. 51).

Esto agrega la posibilidad de que la autobiografía reformulada como otobiografía confíe su firma a un otro futuro, totalmente desconocido, mientras que la escritura en su valor material, se juegue en la contingencia de lo que Derrida (2001) trabaja como la economía postal. El texto otobiográfico, al igual que cualquier otro texto, permanece en el envío, sin un destinatario único. Llevadas a fondo estas implicaciones, seríamos nosotros los lectores del dictado de las memorias de Picahueso quienes, una vez escuchado el mensaje con un oído suficientemente agudo o dispuesto, firmaríamos también el texto que nos ha sido enviado.

\section{Referencias}

Anónimo. (1957). La vida de Lazarillo de Tormes y de sus fortunas y adversidades. Madrid: Afrodisio Aguado.

Cañas-Escalante, A. (12 de diciembre de 1971). Chisporroteos. La República, p. 8.

Chase-Brenes, A. (1975). Narrativa contemporánea de Costa Rica. Costa Rica: Ediciones del Ministerio de Cultura, Juventud y Deportes.

Chavarría Castro, B. (2018). Análisis deconstruccionista de la novela La colina del buey, de José León Sánchez (tesis de maestría). Universidad de Costa Rica, San José, Costa Rica.

Derrida, J. (1985). Otobiographies. The Teaching of Nietzsche and the Politics of the Proper Name. En Autor, The Ear of the Other (pp. 1-38). (Trad. A. Ronell). Nueva York: Schocken Books.

Derrida, J. (2001). La tarjeta postal de Sócrates a Freud y más allá (Trad. H. Silva). México, D.F.: Siglo XXI Editores. 
García-Murillo, G. (1974). La vida en las minas de Abangares y la novela histórica "La colina del buey” de José León Sánchez. Revista de la Universidad de Costa Rica, (38), 87-97.

Guillén, C. (1989). “De la interhistoricidad”. Teorías de la historia literaria (pp. 283-308). Madrid: Espasa-Calpe.

Láscaris-Comneno, C. (1971). José León Sánchez [Presentación de la novela]. En J. L. Sánchez, Picahueso. Costa Rica: Imprenta Lehmann.

Lewandowski, T. (1982). Diccionario de Lingüística. Madrid: Editorial Cátedra.

Quesada-Soto, Á. (2008). Breve historia de la literatura costarricense. Costa Rica: Editorial de la Universidad de Costa Rica.

Rey-Hazas, A. (1990). La novela picaresca. Madrid: Anaya.

Rico, F. (1989). La novela picaresca y el punto de vista. (4. ${ }^{\mathrm{a}}$ ed.). Barcelona: Seix Barral.

Sánchez, J. L. (1971). Picahueso. Costa Rica: Imprenta Lehmann.

Sandoval-de Fonseca, V. (1978). Resumen de literatura costarricense. Costa Rica: Editorial Costa Rica.

Villamía, L. (2011). Sobre la historiografía del género picaresco. Pliegues modernos de la literatura del pobre. Hipertexto, (13), 42-58. Recuperado de https://dialnet.unirioja.es/servlet/articulo? codigo=3727896/

\section{(c) $(7) \ominus$}

Esta obra está bajo una licencia de Creative Commons Reconocimiento-NoComercialSinObraDerivada 4.0 Internacional 